\title{
A Doutrina da Segurança Nacional de Contenção na Guerra Fria: fatores que contribuíram para a participação dos militares na política brasileira (1947- 1969) ${ }^{1}$
}

The National Security Doctrine of Containment in the Cold War and its Contributions to the Participation of Brazilian Military in Politics (1947-1969)

Claudia Stephan ${ }^{2}$

\section{RESUMO}

O artigo analisa a Doutrina da Segurança Nacional brasileira (DSN), institucionalizada em 1949 com a fundação da Escola Superior de Guerra (ESG), à luz da ideologia da bipolaridade do sistema internacional e da Doutrina de Contenção durante a Guerra Fria (1945-1991). O objetivo é elucidar a influência dessa doutrina estadunidense na participação dos militares na política brasileira entre os anos 1947 e 1969. Argumenta-se que a influência deu-se por meio de mecanismos de ingerência na América Latina e no Brasil, culminando no estabelecimento de um Estado de Segurança Nacional em 1964.

Palavras-chave: Doutrina da Segurança Nacional de Contenção; Guerra Fria; Estado de Segurança Nacional; Regime Militar Brasileiro.

\begin{abstract}
The article analyzes the Brazilian National Security Doctrine (DSN), institutionalized in 1949 with the establishment of the War College (ESG), based on the bipolar ideology of the international system and the Containment Doctrine during the Cold War (1945-1991). The aim is to elucidate the influence of the US doctrine on the participation of the military in Brazilian politics between 1947 and 1969. I argue that the US doctrine contributed to the establishment of a Brazilian National Security State in 1964 by means of strategic mechanisms implemented in Latin America and Brazil.
\end{abstract}

Keywords: National Security Doctrine of Containment; Cold War; National Security State; Brazilian Military Regime.

\footnotetext{
${ }^{1}$ Versão expandida e revisada do artigo apresentado no I Seminário Internacional de Ciência Política da UFRGS, Porto Alegre, Brasil, 2015.

2 Internacionalista (UTP), Doutoranda em Ciência Política, Pesquisadora do NEPRI e Coordenadora do GESEG na Universidade Federal do Paraná (UFPR), Curitiba, Brasil.
} 


\section{INTRODUÇÃO}

A Doutrina da Segurança Nacional de Contenção (DSNC) surgiu durante a Guerra fria como estratégia geopolítica dos Estados Unidos para conter a expansão do comunismo e a subversão por meio do alinhamento dos Estados, especialmente da América Latina, ao regime liberal-capitalista e à cooperação para a defesa coletiva do continente americano. Essa estratégia foi formulada como parte da resposta à rivalidade entre as potências emergentes da II Guerra Mundial - Estados Unidos (EUA) e União Soviética (URSS), dentre outras estratégias utilizadas por ambas as potências para disseminar suas visões de uma nova ordem global. Entretanto, desconsideravam as implicações de médio e longo prazo da adoção de tais ideias e práticas em contextos de desigualdade, autoritarismo e instabilidade político-social do então chamado Terceiro Mundo.

No Brasil, a introdução de uma ideologia de contenção do comunismo e da subversão, aliada ao histórico autoritário e intervencionista do Estado, culminou no estabelecimento de um Estado de Segurança Nacional, na institucionalização de princípios e práticas repressivas e na violação de direitos fundamentais de cidadãos brasileiros. 0 artigo apresenta uma análise da Doutrina da Segurança Nacional brasileira (DSN), institucionalizada em 1949 com a fundação da Escola Superior de Guerra (ESG), à luz da ideologia da bipolaridade do sistema internacional e da Doutrina de Contenção durante a Guerra Fria (1945-1991).

O objetivo é elucidar a influência da DSNC estadunidense na participação dos militares brasileiros na política entre os anos 1947 e 1969. Para isso, utilizou-se a metodologia qualitativa de análise histórica (process tracing) em dois níveis: o internacional (contexto da Guerra Fria e estratégia hegemônica dos EUA) e nacional (contexto brasileiro e alinhamento aos EUA). A metodologia escolhida enfatiza a importância de compreender os processos internacionais e sua influência, direta ou indireta, nos eventos nacionais em determinados contextos históricos: a interação entre novas conjunturas internacionais e as decisões nacionais que são afetadas por ideologias, culturas, intercâmbios comerciais, acordos diplomáticos, financeiros e militares e valores universalizados. 
Nesse sentido, o artigo delineia os processos relevantes ao objetivo da pesquisa, deixando de lado os detalhes empíricos já apresentados por outros(as) autores(as). 0 recorte temático da pesquisa focaliza os ideais liberal-capitalistas propagados pela estratégia estadunidense, os mecanismos de ingerência na América Latina e no Brasil, os princípios fundamentais da DSN e suas particularidades no contexto brasileiro. 0 recorte temporal abrange o período de 1947, com a introdução da DSNC ou Doutrina Truman, passando pelo estabelecimento do Estado de Segurança Nacional brasileiro per se no ano de 1964, até a edição do último Ato Institucional durante o regime militar³ em 1969.

Argumenta-se que a influência deu-se por meio da retórica da contenção e de estratégias de ingerência na América Latina e no Brasil, de treinamentos militares no National War College e na US Army School of the Americas (USARSA/SOA) e das relações bilaterais militares, econômicas e tecnológicas. Ademais, a participação do Brasil na II Guerra Mundial despertou o interesse da elite militar pela modernização das forças armadas e a percepção da importância do papel dos militares para o crescimento e o desenvolvimento econômico do país. 0 resultado foi a institucionalização de princípios e práticas de repressão e o estabelecimento de um Estado de Segurança Nacional, em 1964, que suspendeu direitos fundamentais para uma cidadania democrática.

O artigo está organizado em três seções. A primeira contextualiza a Guerra Fria no sistema internacional, a ideologia da bipolaridade e a Doutrina de Contenção, bem como os processos intervenientes resultantes da relação Estados Unidos-Brasil. A segunda seção introduz os princípios fundamentais da Doutrina da Segurança Nacional brasileira, bem como o histórico de sua institucionalização no país pela Escola Superior de Guerra e sua origem na estratégia de contenção estadunidense. E a terceira seção analisa o Estado de Segurança Nacional Brasileiro e as implicações da institucionalização de princípios e práticas de contenção do comunismo e da subversão no país.

\section{A IDEOLOGIA DA BIPOLARIDADE NA POLÍTICA INTERNACIONAL DA GUERRA FRIA (1945-1991)}

\footnotetext{
${ }^{3}$ Há uma vasta literatura que comprova a participação civil na chamada ditadura militar, mas devido ao recorte temático na participação dos militares e a ênfase na origem militar do regime adotado em 1964 utilizaremos apenas as expressões 'regime militar' e 'ditadura' ao invés de 'ditadura civil-militar'.
} 
O período da Guerra Fria ficou conhecido pela rivalidade entre as duas potências emergentes da II Guerra Mundial: os Estados Unidos (EUA) e a União Soviética (URSS). Essa rivalidade expressava-se por meio de uma divisão ideológica do sistema internacional em dois blocos, respectivamente, o liberal-capitalista e o socialistacomunista. A divisão ideológica em duas zonas estratégicas de influência representava o contexto maniqueísta da política e das relações internacionais e a manutenção do equilíbrio de poder mundial.

A bipolaridade do sistema internacional não afetava apenas a esfera política, doméstica e internacional, mas também a esfera econômica, sociocultural e militar. Essa ideologia, vigente durante a Guerra Fria (1945-1991), influenciou os países a se alinharem aos ideais hegemônicos de uma das duas grandes potências. Diversas estratégias foram utilizadas por ambas as potências para disseminar suas visões de uma nova ordem global, entretanto, o recorte de pesquisa focaliza a atuação dos Estados Unidos na América Latina e no Brasil no que concerne à defesa nacional e à segurança internacional.

O período da Guerra fria pode ser dividido em seis fases: início (1945-1947), declaração (1947-1949), auge (1950-1962), détente (1963-1978), retorno (1978-1988) e fim (1989-1991) (NYE JR. 2009, p. 148-155). A disputa acontecia por meio da intimidação, como uma extensão da lógica do equilíbrio de poder, e da contenção, ofensiva e defensiva, via poder militar (guerra ou alianças), poder econômico (blocos ou sanções) e poder brando $^{4}$ (ideias e valores). De um lado, a URSS, potência terrestre e comunista, que tinha como meta a conquista de territórios. Do outro lado, os EUA, potência marítima e liberal, que tinham como meta a expansão e a liderança de uma ordem político-econômica mundial igualmente liberal (NYE Jr., 2009, p. 141-160).

Os EUA saíram da II Guerra Mundial como superpotência e adentraram o reconfigurado sistema internacional com ambições igualmente grandiosas. Preocupavam-se com o fortalecimento da URSS e com uma possível virada na balança de poder. Porém, a rivalidade existente entre as duas superpotências, na realidade, dificilmente se traduziria em um enfrentamento militar (HOBSBAWN, 2005, p. 231).

Algumas razões para a percepção de ameaça soviética podem ser elencadas. Primeiro, a posição geopolítica soviética facilitava ramificações comunistas e expansão

\footnotetext{
${ }^{4}$ Soft power.
} 
territorial (HOOK \& SPANIER, 2010, p. 41). Segundo, a superioridade militar soviética em contingente armado (LUNDESTAD, 2004). Terceiro, a não aceitação do Plano Marshall pela URSS (PAINTER, 1999, p. 22). E, finalmente, o surgimento de diversas revoluções inspiradas pelo comunismo, entre meados da década de 1940 e início da década de 1950, o autoritarismo e as violações de direitos humanos na URSS e a própria corrida armamentista - especialmente a nuclear (REED, 2011, p. 39).

A suposição da ameaça comunista levou os EUA a consolidarem instrumentos de defesa continental que se espalharam pela América Latina. Programas de cooperação foram implantados nas mais diversas regiões, de modo a influenciar os países menos desenvolvidos e com maior propensão ao alinhamento com a URSS. A promoção da segurança coletiva, legitimada pela ONU e pelos acordos bilaterais e multilaterais entre os Estados, facilitou a ampliação dos interesses de segurança nacional estadunidenses que seriam perseguidos via persuasão/cooperação internacional. A retórica da segurança nacional foi utilizada pelos EUA como meio de propagação dos ideais liberal-democráticos para atingir seus objetivos hegemônicos e unilaterais, despertando o interesse da América Latina em criar seus próprios instrumentos de defesa nacional.

Alguns exemplos de instrumentos de ampliação da segurança nacional estadunidense são a Aliança para o Progresso (ALPRO), a criação da Organização dos Estados Americanos (OEA) e o Tratado Interamericano de Assistência Recíproca (TIAR), formalizando o controle assistencialista na região. A grande questão era a disseminação e a manutenção da ideologia liberal-capitalista e do 'American way of life', e o regime democrático dos EUA contribuía para a sustentação do anticomunismo como retórica eleitoral e diplomática na Organização das Nações Unidas (ONU). Surgia uma demanda pela criação de mecanismos políticos que assegurassem a influência dos EUA e, consequentemente, sua hegemonia mundial.

Dentre as estratégias utilizadas está a Doutrina da Segurança Nacional de Contenção (DSNC) ou Doutrina Truman (1947), a qual se traduziu na retórica liberal democrática e anticomunista para negociar diversos acordos militares, econômicos, tecnológicos e de segurança na área de influência dos EUA. Estabeleceu-se, então, um curso de ação para "um rápido fortalecimento político, econômico e militar do mundo 
livre" (TRUMAN, 1950, p. 54): uma política de contenção do comunismo para a América Latina que vigorou entre os anos de 1947 e 1970.

Essa política de contenção visava "conter a propagação do comunismo", considerado uma "ameaça aos interesses dos EUA" (REED, 2011, p. 4). Essa visão acerca dos interesses estadunidenses corrobora a constatação de que a Doutrina Truman "forneceu uma chave para [os Estados Unidos] interpretar[em]" os acontecimentos mundiais unilateralmente, justificando qualquer questionamento de seu status quo ou oposição aos seus princípios e métodos pela via da ameaça soviética (COMBLIN, 1978, p. 40). Algumas das ações de contenção incluíam "o uso de operações secretas (como a orquestração de golpes militares para destituir supostos líderes comunistas), represálias econômicas (como a cessação de ajuda econômica [...] para um dado país) e mesmo o uso de força militar" (REED, 2011, p. 4). A subseção a seguir apresenta os princípios e práticas da estratégia hegemônica dos Estados Unidos durante a Guerra Fria.

\subsection{A Doutrina da Segurança Nacional dos EUA (1947-1970): Estratégias de Defesa e Contenção}

A Doutrina da Segurança Nacional (DSN) não é uma novidade trazida pela Guerra Fria. A novidade estava no conceito de segurança nacional estadunidense que passou a fazer parte da "linguagem comum, a tal ponto que ninguém mais se interroga sobre seu sentido", abstrato e sem definição específica que estabeleça parâmetros e limites (COMBLIN, 1978, p. 55). A luta anticomunista tampouco surge nessa época, pois desde o ano de 1917 havia interesse ocidental na contenção do comunismo (REZNIK, 2004, p. 19). Entretanto, esse interesse intensifica-se após a II Guerra Mundial e ganha novas estratégias de contenção e defesa que serão propagadas de modo intenso pelo continente americano.

\footnotetext{
A política de segurança nacional de um país é determinada por vários fatores, incluindo ameaças externas, geografia, cultura política, capacidades militares, necessidades econômicas, a opinião da elite, a opinião popular (em democracias) e percepções dos líderes acerca dos interesses do país. Esse último fator frequentemente manifesta-se no que tem sido chamado de política externa ou "doutrina" de segurança nacional. A doutrina de segurança nacional serve como um guia por meio do qual os líderes conduzem a política externa de um país. No seu modo mais eficaz, uma doutrina de segurança nacional é o princípio organizador que ajuda estadistas a identificar e priorizar os interesses geopolíticos do seu país (SEMPA, 2004).
} 
A partir de 1947, a cooperação entre EUA - URSS, aliados durante a II Guerra Mundial para derrotar a Alemanha nazista, foi desfeita. As duas superpotências já não tinham interesses comuns para manter a aliança e, assim, o choque entre elas tomava forma. A política externa dos EUA passou, então, por uma reorientação: "longe de sua posição usual de retirada em conflitos regionais não diretamente envolvendo os Estados Unidos, para uma de possível intervenção em conflitos longínquos" (US DEPARTMENT OF STATE, 2015d).

Essa nova conjuntura internacional e consequente reorientação da política externa deram origem a uma nova doutrina ${ }^{5}$ : a da segurança nacional de contenção. Entretanto, a abstração do conceito de segurança nacional permitiu a livre interpretação e a instrumentalização dos princípios da DSN para fins de defesa interna e externa igualmente não definidos: conter a subversão. Algumas diferenciações imprescindíveis que constam na doutrina tradicional de defesa nacional foram eliminadas do novo conceito, abrindo brechas para possíveis violações constitucionais e de direitos humanos:

- Política interna e política externa (inimigo comum);

- Natureza civil e militar (objetos de estratégia)

- Violência e não violência (meios);

- Violência preventiva e violência repressiva (preservação dos interesses nacionais) (COMBLIN, 1978, p. 55 e 63).

A Doutrina Truman inaugurou a contenção ao comunismo e à expansão soviética. De caráter intervencionista, visto que até o discurso do então Presidente Harry S. Truman (1945-1953), em março de 1947, a contenção era mantida pela via diplomática, a nova DSN liberou os EUA de seu típico isolamento. O Plano Marshall, ou Programa de Recuperação Europeia, proposto pelo então Secretário de Estado George C. Marshall, em junho do mesmo ano, foi a primeira estratégia anticomunista da nova política externa (US DEPARTMENT OF STATE, 2015d). A DSNC surgiu como uma contraideologia ao socialismo-comunismo estabelecido e fortalecido na URSS (COMPARATO, 1981, p. 52).

\footnotetext{
${ }^{5}$ Os Estados Unidos tiveram oito doutrinas de segurança nacional: Doutrina do Discurso de Despedida de Washington (1796), Doutrina Monroe (1823), Doutrina do Destino Manifesto (1839), Doutrina da Porta Aberta (1898), Doutrina Offshore Balancer (1917), Doutrina da Contenção (1947), Doutrina da Libertação (1983) e Doutrina da Preempção (2002) (SEMPA, 2004).
} 
No âmbito nacional, os Estados Unidos criaram novas agências governamentais de combate ao comunismo e à subversão. Em julho de 1947, o Congresso estadunidense aprovou o Ato de Segurança Nacional (National Security Act) "para coordenar a política externa, de defesa e nacional por meio do estabelecimento de um Conselho de Segurança Nacional (National Security Council)" (US DEPARTMENT OF STATE, 2015). Foram criados também o Departamento de Defesa ${ }^{6}$ e a Agência Central de Inteligência7 .

Nesse contexto, Truman estendeu a estratégia de contenção à América Latina. Em setembro de 1947, foi assinado o Pacto do Rio ou Tratado Interamericano de Assistência Recíproca8 (TIAR), o qual estabeleceu que "um ataque armado por qualquer Estado deverá ser considerado como um ataque a todos os Estados americanos e, consequentemente, cada uma das partes contratantes compromete-se a auxiliar no cumprimento do [contra-]ataque" (US DEPARTMENT OF STATE, 2015b). Em 1949, Truman lançou um programa de assistência técnica para a América Latina, o Ponto Quatro $^{9}$ (ALLAGIO, 2006, p. 39). Além disso, em abril de 1949, foi criada a Organização do Tratado do Atlântico Norte (OTAN) como estratégia de segurança coletiva (US DEPARTMENT OF STATE, 2015b), direcionada para a Europa.

Em 1953, a contenção adquiriu um viés mais econômico. 0 então Presidente dos EUA, Dwight D. Eisenhower (1953-1961), aproximou-se da América Latina por meio da Organização dos Estados Americanos ${ }^{10}$ (OEA), afirmando que os Estados Unidos, "devido à natureza da tensão que está atormentando o mundo todo", sentiam-se prontos "para ajudar outras nações a melhorar seus padrões de vida e garantir sua segurança" (EISENHOWER, 1953).

Na década de 1960, houve uma mudança na estratégia da política externa dos Estados Unidos em relação aos países do então chamado Terceiro Mundo. Diante da contínua ameaça do comunismo, especialmente no que diz respeito ao regime cubano, e das mobilizações populares na América Latina em face da imensa desigualdade social, surge a teoria da modernização. Pretendia-se aliar os interesses estadunidenses à modernização dos países mais atrasados, acelerando um processo que, supunham os

\footnotetext{
${ }^{6}$ U.S. Department of Defense $(D o D)$.

${ }^{7}$ Central Intelligence Agency (CIA).

${ }^{8}$ Inter-American Treaty Of Reciprocal Assistance (Rio Treaty).

${ }^{9}$ Point Four Program.

10 Organization of American States (OAS).
} 
especialistas, aconteceria em um futuro próximo. Nesse sentido, a nova estratégia uniu as frentes política, econômica e social com a pretensão de criar "uma estabilidade política, uma legitimidade dos regimes democráticos da região, detendo o presumido avanço comunista" (ALLAGIO, 2006, p. 18-19).

Em março de 1961, o então Presidente John F. Kennedy (1961-1963) anunciou a proposta de uma aliança de cooperação para a modernização da América Latina, prevista para durar entre nove e dez anos (REED, 2011, p. 76). A Aliança para o Progresso ${ }^{11}$ (ALPRO) foi implantada em agosto daquele ano, a partir do programa da Carta de Punta Del Este (ALLAGIO, 2006, p. 89). Naquele mesmo ano foi aprovado pelo Congresso estadunidense o Ato de Assistência Externa ${ }^{12}$ para unificar os programas e agências de assistência a países estrangeiros sob os auspícios da Agência dos Estados Unidos para o Desenvolvimento Internacional ${ }^{13}$, fundada em 3 de novembro de 1961 (USAID, 2013).

\begin{abstract}
Superado o medo de uma crescente influência soviética e cubana na América Latina, a Aliança para o Progresso de 1961 a 1969 foi, em essência, um Plano Marshall para a América Latina. Os Estados Unidos prometeram US\$ 20 bilhões de dólares em assistência (subvenções e empréstimos) e instou os governos latino-americanos a fornecerem US\$ 80 bilhões de dólares em fundos de investimento para as suas economias. Foi o maior programa de ajuda dos Estados Unidos para o mundo em desenvolvimento até aquele momento - e apelou para uma reforma substancial das instituições latino-americanas (US DEPARTMENT OF STATE, 2013b).
\end{abstract}

A partir de 1964, a estratégia de segurança nacional estadunidense passa a ser a contrarrevolução, abandonando a ideia de uma possível invasão soviética e redirecionando as forças contra a subversão - infiltrações e revoluções de inspiração comunista, uma espécie de 'guerra invisível' que demandava ações da inteligência. A Operação Condor, que integrou os serviços de inteligência de Argentina, Brasil, Chile, Paraguai e Uruguai, também teve assistência técnica dos EUA.

Nos anos 1970, o Estado-Maior do Exército brasileiro e a CIA estabeleceram uma rede internacional com (e entre) os países do Cone Sul "para troca de informações e operações conjuntas visando a repressão às organizações ditas subversivas [...], a qual estava estruturada, pelo menos, desde os anos 1940" (REZNIK, 2004, p. 20-21). As

\footnotetext{
11 1961-1969 Alliance for Progress.

12 Foreign Assistance Act of 1961.

13 United States Agency for International Development (USAID).
} 
intervenções anticomunistas na América Latina começaram a ser gradualmente reduzidas, ainda que não tivessem cessado completamente. De qualquer maneira, a ideologia anticomunista da DSNC estadunidense já havia se espalhado pela América Latina e influenciado militares e civis que davam continuidade aos seus princípios, ainda que tentassem adaptá-los à realidade de seus países.

\begin{abstract}
Essa estratégia contrarrevolucionária [...] serviu sobretudo para formar uma escolástica militar rígida, um manual da guerra revolucionário que se tornou, desde 1961, a base do ensinamento dado aos exércitos latino-americanos. De 1965 em diante, o ensino dessa escolástica superou, nas escolas militares, o ensino consagrado a outras formas de guerra. E um grande número de oficiais aprendeu a interpretar os acontecimentos em seu país através do esquema convencional de guerra revolucionária. Eis então a explicação para a extraordinária distância entre a realidade latino-americana e o aparelho conceitual de que dispõem os militares da Segurança Nacional para interpretarem [a] realidade. Pois afinal não houve e nem há, na América Latina, nada que se pareça, nem de longe, com uma guerra revolucionária no sentido de Mao (COMBLIN, 1978, p. 47).
\end{abstract}

Seja pelo interesse no crescimento e desenvolvimento do país, seja pela identificação com a possibilidade de avanço por meio das relações bilaterais Brasil - EUA, o fato é que a doutrina de segurança nacional estadunidense conseguiu ser incorporada nos Estados latino-americanos com tal espontaneidade que logrou atingir seus fins hegemônicos. A próxima seção elucida como essa incorporação aconteceu no Brasil, a fim de discutir as intenções hegemônicas estadunidenses face ao interesse militar brasileiro pela modernização das forças armadas e uma renovada percepção da importância do papel dos militares para o progresso do país.

\title{
2. A DOUTRINA DA SEGURANÇA NACIONAL DE CONTENÇÃO NO CONTEXTO BRASILEIRO
}

A retórica maniqueísta capitalismo-comunismo e democracia-autocracia, presente em todas as esferas da política nacional e internacional, serviu de apoio à estratégia de contenção. Entretanto, conforme citado anteriormente, a Doutrina da Segurança Nacional e a luta anticomunista, tanto nos Estados Unidos quanto no Brasil, não foram novidades trazidas pelo fim da II Guerra Mundial.

O Brasil já experimentava o anticomunismo desde a década de 1930. Em 1933, já havia sido criada a Delegacia Especial de Segurança Política e Social (DESPS), como parte da luta anticomunista (REZNIK, 2004, p. 19-31). A chamada 'conspiração comunista de 
1935’ precedeu o golpe de 1937 que colocou Getúlio Vargas no poder, dando início a uma série de leis que definiam os crimes contra a ordem política e social - as leis de segurança nacional. Em 1953, foi promulgada uma nova Lei de Segurança Nacional nos moldes da competição ideológica da Guerra Fria, sendo reformulada nos anos de 1967, 1969, 1972, 1978 e 1983.

\begin{abstract}
A Lei de Segurança Nacional, promulgada em 4 de abril de 1935, definia crimes contra a ordem política e social. Sua principal finalidade era transferir para uma legislação especial os crimes contra a segurança do Estado, submetendo-os a um regime mais rigoroso, com o abandono das garantias processuais. A LSN foi aprovada, após tramitar por longo período no Congresso e ser objeto de acirrados debates, num contexto de crescente radicalização política, pouco depois de os setores de esquerda terem fundado a Aliança Nacional Libertadora. Nos anos seguintes à sua promulgação foi aperfeiçoada pelo governo Vargas, tornando-se cada vez mais rigorosa e detalhada. Em setembro de 1936, sua aplicação foi reforçada com a criação do Tribunal de Segurança Nacional. Após a queda da ditadura do Estado Novo em 1945, a Lei de Segurança Nacional foi mantida nas Constituições brasileiras que se sucederam (FGV/CPDOC, 2015).
\end{abstract}

O temor das elites governantes ao populismo (como veio a ser chamada a crescente participação popular entre 1930 e 1946), embutido nos discursos dos líderes brasileiros, contribuiu para a adoção da doutrina de segurança nacional porque reforçava o caráter emergencial de sua implantação no Brasil como princípio estabilizador sociopolítico (REZNIK, 2004, p. 18). Alguns pesquisadores brasileiros, como Jacob Gorender, identificam o período anterior ao golpe militar (1960 a 1964) como o auge da luta dos trabalhadores no Brasil e de maior instabilidade institucional da "ordem burguesa e imperialista", constituindo uma verdadeira ameaça ao status quo da época suficiente para que a esquerda fosse contida (FICO, 2004, p. 49).

\footnotetext{
A ira anticomunista resvalava para os movimentos sociais populares. Assim, a queda de Vargas em 1945 pode ser creditada à sua maior liberalização em relação aos sindicatos e à sua maior aproximação com a agitação da massa queremista; [...] a intensa campanha antijanguista nos anos $1950 \mathrm{fez}$-se sob o epíteto "comuno-capitalista". [...] A cidadania, nesse quadro, foi cerceada não apenas pela exclusão da enorme gama de analfabetos incapacitados para votar; [...] também foi cerceada pela intolerância propriamente política, pelo veto à participação na polis de indivíduos e grupos que divergiam ideologicamente. Nessas condições, houve uma (re)qualificação da liberdade de manifestação, expressão e associação, requisitos básicos para discurso e prática democráticos. [...] A democracia do pós-guerra estava constrangida pela Guerra Fria. Nesse contexto os comunistas eram inimigos internos, enquadravam-se numa lei de segurança por serem "antinacionais" (REZNIK, 2004, p. 19-26).
} 
A Doutrina da Segurança Nacional funcionou não apenas como instrumento de manutenção do status quo dessas elites, mas, também, como meio de propagação dos ideais democráticos estadunidenses - que não se adaptariam tão facilmente no Brasil. A estratégia estadunidense influenciou as elites civil e militar brasileiras a adotarem seus princípios liberais, democráticos e de segurança nacional por meio da doutrina de contenção e de acordos de cooperação técnica, econômica e militar.

O fato do Brasil encontrar-se geograficamente no Ocidente parece representar, para alguns autores, como Joseph Comblin (1978, p. 30), a impossibilidade de "antagonismo entre a luta contra o comunismo e a busca do Brasil-potência". Mesmo entre os geopolíticos da época predominava o fatalismo do alinhamento brasileiro aos Estados Unidos. Entretanto, é importante ressaltar que, por essa mesma razão, os EUA buscaram estender suas estratégias de contenção ao Brasil por meio da retórica liberal-democrática.

A ideologia da segurança nacional tinha por finalidade mostrar o "estado de guerra" no qual também se encontravam os povos latino-americanos e de "prepará-los para agir em consequência" (FICO, 2011). Se é possível constatar que uma parcela de militares e civis estava mesmo convencida da ameaça comunista, e se tal ameaça nunca foi comprovada pela ligação de algum líder brasileiro com o comunismo soviético (FICO, 2011), é possível afirmar que a retórica estadunidense havia cumprido seu propósito de ser assimilada no âmbito político-militar brasileiro. A próxima subseção discute a nacionalização da DSNC no Brasil.

\subsection{A Institucionalização da Doutrina da Segurança Nacional de Contenção no Brasil}

A introdução da Doutrina da Segurança Nacional de Contenção (DSNC) no Brasil deu-se por meio da fundação da Escola Superior de Guerra (ESG) em 1949, Lei № 785, inspirada nos moldes da Escola Nacional de Guerra dos Estados Unidos (National War College) (REZNIK, 2004, p. 32-33). A DSN brasileira constituía-se de quatro elementos fundamentais: objetivos nacionais, segurança nacional, poder nacional e estratégia nacional (COMBLIN, 1978, p. 50).

Os objetivos nacionais são os "interesses e aspirações em determinado estágio de evolução nacional [...], em última análise, os interesses e aspirações mais relevantes da comunidade nacional". No Brasil resumiam-se em integridade territorial, integridade 
nacional, democracia, progresso, paz social e soberania (GURGEL, 1975, p. 70-76). A segurança nacional "é a garantia proporcionada pelo Estado para a conquista e/ou manutenção dos objetivos nacionais, a despeito de antagonismos ou pressões" (GURGEL, 1975, p. 138). O poder nacional "é a expressão integrada dos meios de toda ordem (políticos, econômicos, psicossociais e militares), de que dispõe efetivamente a Nação, para alcançar e/ou manter interna e externamente os objetivos nacionais" (GURGEL, 1975, p. 83). O quarto elemento da DSN, a estratégia nacional, é conceituada como "a arte de preparar e aplicar o poder nacional para obter ou manter os objetivos fixados pela política nacional" (GURGEL, 1975, p. 81).

A ESG é fruto da experiência da Força Expedicionária Brasileira (FEB) na II Guerra Mundial e do renovado interesse da elite militar em encontrar um modelo de governo tão avançado quanto o modelo democrático e industrial que transformou os EUA em uma potência internacional (GURGEL, 1975, p. 30). 0 objetivo era sistematizar os estudos de defesa "de modo a influenciar a maneira como a sociedade pensava sobre temas como soberania nacional e integridade territorial" (MD, 2014).

\begin{abstract}
A partir desta constatação, brasileiros como o Marechal Salvador César Obino, que, após a II Guerra, estudou no National War College, nos Estados Unidos, voltaram para casa com um único propósito: transformar o Brasil num país forte e moderno, capaz de proteger sua soberania, suas riquezas e o seu povo. Nesse contexto, em [20 de agosto de] 1949, nascia a Escola Superior de Guerra [...]. Muito mais do que militares treinados para combate, armas e equipamentos, a escola surgiu com a missão de reunir a elite pensante do país e convidá-la a desenvolver um método de planejamento próprio, capaz de transformar o país numa grande potência (MD, 2014).
\end{abstract}

A intenção dos envolvidos na criação da ESG transparecia na declaração do General Juarez Távora, segundo comandante da ESG: dizia que a função da escola era "insuflar na consciência de nossa elite [...] uma compreensão ampla e uniforme sobre os problemas da segurança nacional, capaz de se condensar [...] numa adequada doutrina de segurança nacional" (1953/1983; REZNIK, 2004, p. 34). "A [...] tese do Brasil-potência, prontamente ingurgitada pelos nossos políticos, diplomatas e jornalistas, é um simples precipitado dessa reação ideológica [...] de idolatria do poder e da potência", importada da doutrina da segurança estadunidense (COMPARAT0, 1981, p. 52).

A participação civil também fazia parte do propósito da ESG: entre os anos 1950 e 1967, 646 diplomados dos 1.276 eram civis. Após a instauração do regime militar, em 
1964, "599 altos oficiais militares, 224 industriais, 200 ministros de Estado e burocratas de primeiro escalão, 97 diretores de órgãos governamentais, 39 parlamentares, 23 juízes federais e estaduais e 107 tecnocratas" formados pela ESG assumiram cargos em instituições políticas e econômicas governamentais (STEPAN, 1975, p. 129-130).

A influência da doutrina de segurança estadunidense na DSN brasileira manifesta-se na evolução do próprio conceito de segurança em relação ao desenvolvimento, além da tradicional abertura às influências externas, uma vez que havia grande entusiasmo pela organização, planejamento e desenvolvimento dos Estados Unidos, presenciados por oficiais e pela Força Expedicionária Brasileira (FEB) quando em visitas e cursos preparatórios para a participação na II Guerra Mundial (GURGEL, 1975). Desde então havia um anseio pela modernização do aparato militar no Brasil nos moldes estadunidenses.

A estratégia militar dos Estados Unidos para a América Latina tinha três frentes, as quais "foram meios de difusão extremamente penetrantes para a ideologia da segurança nacional e da preparação eficiente do aperfeiçoamento de um sistema políticomilitar de um novo tipo, o Estado de segurança nacional" (COMBLIN, 1975, p. 134). A primeira frente de influência dos EUA para os exércitos latino-americanos foi a integração das forças armadas do continente americano, a segunda frente foi a ajuda militar e a venda de armamentos, e a terceira frente foram os programas de formação militar (COMBLIN, 1975, p. 134-141). Esses objetivos estratégicos foram cumpridos por meio da Comissão Mista Brasil-EUA para o Desenvolvimento Econômico (Abbink Commission), da Comissão Militar Mista Brasil-EUA (CMMBEU) e da Comissão Mista de Defesa Brasil-EUA, as quais garantiram a cooperação e o alinhamento entre os dois Estados em troca de financiamentos, assistência técnica, armamentos, treinamento etc.

0 treinamento militar acontecia no National War College, na USARSA/SOA conhecida como 'Escola das Américas'14 - e em outras instituições militares nos EUA e no Brasil, como a ESG. "Desde 1961, [...] a USARSA/SOA [...] formou 33.147 militares latinoamericanos. [...] Em fins de 1975, segundo as estatísticas do Departamento de Defesa,

\footnotetext{
${ }^{14}$ A Escola das Américas foi criada em 1946 e renomeada e realocada em 2001, devido à repercussão negativa na mídia e nas sociedades latino-americanas em relação aos treinamentos e métodos ensinados, que foram divulgados a partir da desclassificação de seus manuais de instrução.
} 
71.651 militares latino-americanos haviam passado por uma dessas escolas" (COMBLIN, 1975, p. 140).

Os manuais da USARSA/SOA tratavam desde métodos e técnicas de interrogação de suspeitos, incluindo meios psicológicos e físicos com e sem uso de violência e/ou narcóticos (Kubark Counterintelligence Interrogation, 1963) até doutrinas de guerra e ideologia, como Guerra Revolucionaria Guerrillera e Ideologia Comunista. Os manuais da ESG versavam sobre: Introdução ao Estudo da Guerra Revolucionária (1959); Conceituação de Guerra Insurrecional, Revolucionária, Subversiva, Ação e Guerra Psicológica e Guerra fria (1961); Aspectos da Guerra Contemporânea - A Guerra Revolucionária (1969); e Pequeno Escalão nas Operações Contraguerrilhas (1969).

A predominância da estratégia contrarrevolucionária, que já vinha sendo ensinada aos exércitos latino-americanos desde 1961, explica “a distância entre a realidade latino-americana e o aparelho conceitual de que [dispunham] os militares da segurança nacional. Pois afinal não houve e nem há, na América Latina, nada que se pareça [...] com uma guerra revolucionária no sentido de Mao" (COMBLIN, 1978, p. 47).

O interesse brasileiro pelo desenvolvimento nacional e pelo reaparelhamento das Forças Armadas foi levado às negociações para o alinhamento do Brasil aos Estados Unidos e, posteriormente, aos Aliados e culminou em acordos de concessão de créditos, financiamento da Companhia Siderúrgica Nacional e reaparelhamento militar em troca do fornecimento de materiais estratégicos e o estacionamento de tropas militares dos Estados Unidos no Nordeste (FGV, 2015a).

0 investimento na economia brasileira, particularmente nos setores de infraestrutura de transportes, energia e indústria agrícola, também fez parte das negociações Brasil-EUA via Comissão Mista de Desenvolvimento Econômico (19511953). A condição para o financiamento de aproximadamente 387 milhões de dólares pelo Banco Interamericano de Reconstrução e Desenvolvimento (BIRD) ou pelo ExportImport Bank (Eximbank), como parte do programa estadunidense Ponto Quatro de assistência técnica para a América Latina, era que o Brasil mantivesse a exportação de minerais estratégicos, como manganês e areias monazíticas (D’Araujo, 2016). 
sobre a qual começou a se falar em 1959-1960, e que foi adotada por Kennedy em 1961. Nesse momento os militares latino-americanos foram preparados e estimulados para assumir o poder em seus respectivos países. A estratégia ensinada incluía a tomada do poder e a formação de um governo militar autoritário, baseado em todos os temas da segurança nacional (COMBLIN, 1975, p. 142).

O suporte a golpes militares na América Latina se fortaleceu, apesar do discurso democrático contra governos não eleitos, mas agora sob o lema da "salvação pelo militarismo, que é visto como força de progresso e modernização ordenada" e também "devido às suas funções normalmente conservadoras e anticomunistas" (SCHMITTER, 1973, p. 39). A profissionalização, consequente politização e a ênfase contrarrevolucionária na ação cívica dos militares teve papel preponderante nessa mudança de paradigma (STEPAN, 1971/1973; COMBLIN, 1975, p. 142-143).

É importante enfatizar que a negociação da ajuda externa dos EUA não era unanimidade na elite militar e civil, especialmente em relação à exploração de petróleo por empresas estrangeiras - um dos grandes interesses estadunidenses na região. Portanto, não é possível pensar o setor militar (mesmo o civil) como homogêneo e completamente voltado às ideologias estrangeiras. Os nacionalistas buscavam autonomia frente aos EUA, visando o desenvolvimento industrial com alguma reforma social. Os chamados "entreguistas" seguiam os princípios da ESG, da segurança nacional e do liberalismo econômico alinhado aos EUA, com base nas vantagens comparativas (exportação de commodities) (VIZENTINI, 2012, p. 13).

\begin{abstract}
A Doutrina de Segurança Nacional, largamente aplicada no plano interno, externamente limitou-se ao discurso e a uns poucos episódios concretos. Isso levou muitos analistas a estabelecer uma relação mecânica entre a política conservadora interna e externa identificada como subserviente e pró-americana. Contudo, como o neoliberalismo futuramente viria a demonstrar, no regime militar sobreviveu a noção do projeto nacional de desenvolvimento e [...] a busca de autonomia internacional. A ideia de construir uma potência média industrializada, que remontava ao tenentismo, foi uma orientação do regime [militar de 1964] (VIZENTINI, 2012, p. 39).
\end{abstract}

Enfim, a DSNC per se não foi responsável pela instauração de um novo regime militar no Brasil, mas contribuiu para a crescente valorização do papel da instituição militar para a estabilidade socioeconômica e para a institucionalização daqueles princípios e métodos de contenção no cotidiano político-militar brasileiro. "Setores e 
entidades democráticas da sociedade brasileira, como a Ordem dos Advogados do Brasil, sempre se opuseram à sua vigência, denunciando [a DSN] como um instrumento limitador das garantias individuais e do regime democrático" (FGV/CPDOC, 2015). A última seção analisa o institucionalizado Estado de Segurança Nacional no Brasil e as implicações da nacionalização de princípios e práticas repressivas em um país de histórico intervencionista e autoritário.

\section{0 ESTADO DE SEGURANÇA NACIONAL BRASILEIRO E SUAS IMPLICAÇÕES}

A intervenção militar de 1964 inaugurou o Estado de Segurança Nacional no Brasil, com a institucionalização de um regime de natureza autoritária e baseado nos princípios de contenção do comunismo (inimigo externo) e da subversão (inimigo interno). 0 contexto sociopolítico brasileiro era de polarização, tanto na sociedade quanto entre os próprios militares: nacionalistas versus "entreguistas", a direita brasileira mobilizada contra o governo 'de esquerda', os movimentos sociais radicalizados diante da falta de perspectiva de reformas sociais, empresas estrangeiras ineficientes, crise econômica e a renúncia do então Presidente Jânio Quadros - crítico do "alinhamento automático" aos Estados Unidos e formulador da Política Externa Independente (PEI) (VIZENTINI, 2012, p. 39).

Os mecanismos de cooperação e assistência internacionais, criados a partir da estratégia de contenção e defesa estadunidense, contribuíram para a propagação de valores e princípios repressivos. A retórica amigo-inimigo era reproduzida por esses mesmos mecanismos, sem levar em consideração as diferenças históricas, culturais e a grande desigualdade social do país - e de toda a zona de influência latino-americana. "0 exército transformou-se em força de ocupação dentro de seu próprio país e o povo em inimigo real ou potencial" (MONTAGNA, 1986, p. 35 e 38).

O histórico intervencionista do exército na política brasileira não era um sinal de cumprimento dos processos formais de qualquer regramento ou legislação interna estabelecida. Essa "tradição" de intervenções militares vem desde o Império (1822-1889), com a derrubada da Monarquia e a proclamação da República, passando pela I República (1889-1930), com a Revolução de 1930 que leva Getúlio Vargas ao poder e seguindo com o envolvimento do exército em 61 agitações, 17 protestos e 16 revoltas até a deposição de 
Vargas (1945). Foram 94 movimentos militares (generais, oficiais, praças e civis) em apenas 15 anos (CARVALHO, 1982, p. 113; MONTAGNA, 1986, p. 34).

O período seguinte (1945-1964) foi marcado pela democracia aparente, populismo, instabilidade político-social e contínuo envolvimento dos militares na política. Com a tomada de poder em 1964, os militares passaram de poder moderador temporário para poder executivo permanente. Durante o governo dos militares (1964-1984) foi instaurada a ditadura e o rompimento com os princípios do Estado Democrático de Direito, com o propósito de manutenção da ordem político-social, do progresso e da contenção da subversão.

As consequências desta "tradição" intervencionista foram a despolitização do povo, o nacionalismo sentimental e ufanista (Campanha Pra Frente Brasil), a construção de uma máquina político-militar capaz de se reproduzir independentemente de outros grupos ou partidos (Arena/Forças Armadas), e o apoio total das elites econômicas, alinhadas com a 'linha dura' para resolver seus problemas financeiros (incentivos fiscais) e de amordaçamento da mão de obra (arrocho salarial e intervenção nos sindicatos).

A democracia convivia aos trancos e barrancos com os princípios da segurança nacional. Um país que ainda não havia experimentado efetivamente as etapas iniciais e essenciais do debate político democrático (diversidade ideológica, liberdade de expressão e de participação política e contestação), pelas quais passaram os países do então chamado Primeiro Mundo, teria que "caminhar ao sabor dos acontecimentos imediatos" (REZNIK, 2004, p. 40).

A funcionalidade da DSN "implica no afastamento dos perigos, antagonismos e pressões que afrontam a Nação" (PESSOA, 1971, p. 99), elementos inerentes a qualquer democracia, mas que tiveram uma leitura unilateral. No Brasil, desde sua institucionalização na ESG, em 1949, foram 15 anos de doutrinação, aperfeiçoamento e nacionalização dos princípios autoritários, antagônicos à diversidade ideológica e à contestação/oposição, que [foram] aplicados a partir de 1964 e durante os anos da ditadura militar (COMBLIN, 1975, p. 151; SADER, 2004).

O propósito da tomada de poder pelos militares era restabelecer a ordem política e social, conter os ideais comunistas e a subversão, dispersar movimentos de oposição ao projeto desenvolvimentista e tornar-se uma potência econômica relevante na política 
internacional. A eliminação das forças de oposição e de um poder político popular ficou por conta da repressão, legalizada ou clandestina, aos dirigentes sindicais operários e rurais, aos líderes estudantis e padres ligados aos movimentos sociais, à Igreja e à Universidade, e da cassação de direitos políticos e suspensão de garantias individuais, via Atos Institucionais (COMBLIN, 1975, p. 161-162).

Nesse sentido, os Atos Institucionais (AI) foram os principais instrumentos para legitimar a tomada e a consequente manutenção dos militares no poder - ao contrário da 'volta à normalidade democrática' que o discurso inicial previa, a supressão de direitos fundamentais e a consequente violação de direitos humanos. Os AI refletem a nacionalização da DSNC estadunidense, o conteúdo dos treinamentos militares, a noção de nação homogênea e passiva, a segurança nacional a qualquer custo - mesmo humano. Porém, exacerbada pelo histórico autoritário e pelo ufanismo que marcou o regime militar.

\begin{abstract}
O fundamento teórico na Doutrina da Segurança Nacional que embasa o modelo de governo procurado pelo grupo da ESG, "[i]dentifica Estado com a Nação. 0 Estado é a parte ativa, a Nação é o passivo, composto do Poder Nacional, que vem a ser todos os recursos tanto materiais quanto humanos da Nação, já existentes ou em potencial: é a população, recursos, território, poder espiritual, moral. A nação resume-se em uma única vontade, que é forjada, introjetada, de acordo com o passado histórico, de acordo com as tradições, o posicionamento geopolítico, a moral; ocorre que as massas não têm consciência destes elementos, por isso o estado deve forjar uma vontade nacional", como parte ativa, bem como estabelecer os objetivos nacionais. 0 estabelecimento destes objetivos nacionais é feito, segundo Golbery, por uma elite dirigente - treinada na ESG - melhor equipada para a ação política e para manejar os controles sociais, visando educar o povo para a compreensão e aceitação dos objetivos estabelecidos pela elite (FERRARI, p. 10 apud MONTAGNA, 1986, p. 36-37) ${ }^{15}$.
\end{abstract}

Os AI foram normas instituídas durante a ditadura, no período de 1964 a 1969, "editadas pelos Comandantes-em-Chefe do Exército, da Marinha e da Aeronáutica ou pelo Presidente da República, com o respaldo do Conselho de Segurança Nacional" (BRASIL, 2016). Nesse intervalo de cinco anos, foram decretados 17 Atos Institucionais que vigoraram até o final do regime militar, em 1985, representando o momento mais repressivo da história democrática do Brasil no pós-II Guerra Mundial.

Os 21 anos de ditadura militar no Brasil podem ser divididos em três fases: $1^{\underline{a}}$ ) legalização do regime autoritário (1964-1968); 2ª̣) recrudescimento da repressão e da

${ }^{15} 0$ texto original de Teresinha Ferrari não está disponível (mimeografado). 
violência estatal contra opositores (1969-1978); e 3aa $)$ reabertura política (1979-1985) (MEMÓRIAS..., 2016). A fase de legalização do regime, que interessa para o recorte temático-temporal da pesquisa, permitiu legitimar a tomada de poder e as conseguintes ações repressivas que viriam com a manutenção do status quo pelos militares do novo governo brasileiro.

Os AI foram os instrumentos de legitimação do regime militar, a partir do Ato Institucional № 1 de 1964, o qual modifica a Constituição de 1946 e dá início à participação de fato dos militares na política brasileira. 0 Quadro 1 resume o conteúdo dessa norma.

QUADRO 1 - ATO INSTITUCIONAL № 1 (1964)

\begin{tabular}{|c|c|}
\hline ATO & $\begin{array}{c}\text { RESUMO DO CONTEÚDO } \\
\text { (elaborado pelo Centro de Estudos) }\end{array}$ \\
\hline $\begin{array}{l}\text { Ato Institucional no } 1 \text {, de } 9 \text { de } \\
\text { abril de } 1964 \text {. }\end{array}$ & $\begin{array}{l}\text { Modifica a Constituição do Brasil de } 1946 \text { quanto à eleição, ao mandato e aos } \\
\text { poderes do Presidente da República; confere aos Comandantes-em-chefe das } \\
\text { Forças Armadas o poder de suspender direitos políticos e cassar mandatos } \\
\text { legislativos, excluída a apreciação judicial desses atos; e dá outras providências. }\end{array}$ \\
\hline
\end{tabular}

Fonte: BRASIL - Portal da Legislação do Governo Federal (2016)

O AI № 2 de 1965 tornou as eleições presidenciais indiretas, cassou e suspendeu direitos políticos, extinguiu e manipulou a criação de novos partidos e determinou que o julgamento de civis pela Lei de Segurança Nacional fosse transferido para a Justiça Militar. Resumidamente (ver Quadro 2), “ampliou os poderes arbitrários do presidente da República para impor estado de sítio e intervir nos estados” (MEMÓRIAS..., 2016).

QUADRO 2 - ATO INSTITUCIONAL № 2 (1965)

\begin{tabular}{|c|c|}
\hline ATO & $\begin{array}{c}\text { RESUMO DO CONTEÚDO } \\
\text { (elaborado pelo Centro de Estudos) }\end{array}$ \\
\hline Ato Institucional no 2, de 27 de \\
outubro de 1965. & $\begin{array}{l}\text { Modifica a Constituição do Brasil de 1946 quanto ao processo legislativo, às } \\
\text { eleições, aos poderes do Presidente da República, à organização dos três Poderes; } \\
\text { suspende garantias de vitaliciedade, inamovibilidade, estabilidade e a de exercício } \\
\text { em funções por tempo certo; exclui da apreciação judicial atos praticados de acordo } \\
\text { com suas normas e Atos Complementares decorrentes; e dá outras providências. }\end{array}$ \\
\hline
\end{tabular}

Fonte: BRASIL - Portal da Legislação do Governo Federal (2016) 
Os AI № 3 e № 4 de 1966, respectivamente, tornou indiretas as eleições estaduais e municipais, decidiu por novas cassações e pela revogação da Constituição de 1946 e convocou o Congresso para debater o projeto de uma nova constituição, aprovada em 1967 (MEMÓRIAS..., 2016) - conforme mostra o Quadro 3.

QUADRO 3 - ATOS INSTITUCIONAIS № 3 E № 4 (1966)

\begin{tabular}{|c|c|}
\hline ATO & $\begin{array}{c}\text { RESUMO DO CONTEÚDo } \\
\text { (elaborado pelo Centro de Estudos) }\end{array}$ \\
\hline $\begin{array}{c}\text { Ato Institucional no 3, de 5 de } \\
\text { fevereiro de 1966. }\end{array}$ & $\begin{array}{l}\text { Dispõe sobre eleições indiretas nacionais, estaduais e municipais; permite que } \\
\text { Senadores e Deputados Federais ou Estaduais, com prévia licença, exerçam o cargo } \\
\text { de Prefeito de capital de Estado; exclui da apreciação judicial atos praticados de } \\
\text { acordo com suas normas e Atos Complementares decorrentes. }\end{array}$ \\
\hline $\begin{array}{c}\text { Ato Institucional no 4, de 12 de } \\
\text { dezembro de 1966. }\end{array}$ & $\begin{array}{c}\text { Convoca o Congresso Nacional para discussão, votação e promulgação do Projeto } \\
\text { de Constituição apresentado pelo Presidente da República e dá outras providências. }\end{array}$ \\
\hline
\end{tabular}

Fonte: BRASIL - Portal da Legislação do Governo Federal (2016)

O AI № 5, o mais conhecido dos atos da ditadura, foi uma resposta dos militares a todo tipo de oposição ao governo, desde notas da imprensa (censura) até protestos de movimentos estudantis (repressão). Com essa norma, instituíram-se práticas arbitrárias que fechariam o Congresso e violariam garantias constitucionais elementares, conforme resume o Quadro 4. A partir do chamado AI-5, o presidente (General) "passou a acumular poderes absolutos. E começou a fazer uso deles, caracterizando um período de arbítrio completo. [...] 0 sistema de segurança exacerbou as ações de violência, desrespeitando as próprias leis do regime, com a justificativa de que se vivia uma 'guerra revolucionária' “ (MEMÓRIAS..., 2016).

QUADRO 4 - ATO INSTITUCIONAL № 5 (1968) 


\begin{tabular}{|c|l|}
\hline ATO & \multicolumn{1}{|c|}{$\begin{array}{c}\text { RESUMO DO CONTEÚDO } \\
\text { (elaborado pelo Centro de Estudos) }\end{array}$} \\
\hline \multirow{2}{*}{$\begin{array}{c}\text { Ato Institucional no 5, de 13 de } \\
\text { dezembro de 1968. }\end{array}$} & $\begin{array}{l}\text { Suspende a garantia do habeas corpus para determinados crimes; dispõe sobre os } \\
\text { poderes do Presidente da República de decretar: estado de sítio, nos casos previstos } \\
\text { na Constituição Federal de 1967; intervenção federal, sem os limites } \\
\text { constitucionais; suspensão de direitos políticos e restrição ao exercício de qualquer } \\
\text { direito público ou privado; cassação de mandatos eletivos; recesso do Congresso } \\
\text { Nacional, das Assembleias Legislativas e das Câmaras de Vereadores; exclui da } \\
\text { apreciaça judicial atos praticados de acordo com suas normas e Atos } \\
\text { Complementares decorrentes; e dá outras providências. }\end{array}$ \\
\hline
\end{tabular}

Fonte: BRASIL - Portal da Legislação do Governo Federal (2016)

Os conseguintes AI № 6 a № 17 de 1969 foram medidas tomadas pelo regime militar para conter e reprimir a oposição por meio de normas que justificavam as ações repressivas e/ou violentas por parte do Estado, como a reformulação e maior rigidez da Lei de Segurança Nacional (MEMÓRIAS..., 2016). O Quadro 5 apresenta um resumo de cada um desses atos.

QUADRO 5 - ATOS INSTITUCIONAIS № 6 A № 17 (1969) 


\begin{tabular}{|c|c|}
\hline ATO & $\begin{array}{l}\text { RESUMO DO CONTEÚDO } \\
\text { (elaborado pelo Centro de Estudos) }\end{array}$ \\
\hline $\begin{array}{l}\text { Ato Institucional } \mathrm{n}^{\circ} 6 \text {, de } 1^{\circ} \text { de } \\
\quad \text { fevereiro de } 1969 .\end{array}$ & $\begin{array}{l}\text { Dá nova redação aos artigos 113,114 e } 122 \text { da Constituição Federal de 1967; ratifica } \\
\text { as Emendas Constitucionais feitas por Atos Complementares subsequentes ao Ato } \\
\text { Institucional no } 5 \text {; exclui da apreciação judicial atos praticados de acordo com suas } \\
\text { normas e Atos Complementares decorrentes; e dá outras providências. }\end{array}$ \\
\hline $\begin{array}{l}\text { Ato Institucional no } 7 \text {, de } 26 \text { de } \\
\quad \text { fevereiro de } 1969 \text {. }\end{array}$ & $\begin{array}{l}\text { Estabelece normas sobre remuneração de Deputados Estaduais e Vereadores; } \\
\text { dispõe sobre casos de vacância de cargos de Prefeito e Vice-Prefeito; suspende } \\
\text { quaisquer eleições parciais para cargos executivos ou legislativos da União, dos } \\
\text { Estados, dos Territórios e dos Municípios; exclui da apreciação judicial atos } \\
\text { praticados de acordo com suas normas e Atos Complementares decorrentes; e dá } \\
\text { outras providências. }\end{array}$ \\
\hline $\begin{array}{l}\text { Ato Institucional } \mathrm{n}^{\circ} 8 \text {, de } 2 \text { de } \\
\text { abril de } 1969 \text {. }\end{array}$ & $\begin{array}{l}\text { Atribui competência para realizar Reforma Administrativa ao Poder Executivo dos } \\
\text { Estados, do Distrito Federal e dos Municípios de população superior a duzentos mil } \\
\text { habitantes; e dá outras providências. }\end{array}$ \\
\hline $\begin{array}{l}\text { Ato Institucional n² 9, de } 25 \text { de } \\
\text { abril de } 1969 .\end{array}$ & $\begin{array}{l}\text { Dá nova redação ao artigo } 157 \text { da Constituição Federal de 1967, que dispõe sobre } \\
\text { desapropriação de imóveis e territórios rurais. }\end{array}$ \\
\hline $\begin{array}{l}\text { Ato Institucional no } 10 \text {, de } 16 \text { de } \\
\text { maio de } 1969 .\end{array}$ & $\begin{array}{l}\text { Dispõe sobre as consequências da suspensão dos direitos políticos e da cassação } \\
\text { dos mandatos eletivos federais, estaduais e municipais; e dá outras providências. }\end{array}$ \\
\hline $\begin{array}{l}\text { Ato Institucional no } 11 \text {, de } 14 \text { de } \\
\quad \text { agosto de } 1969 \text {. }\end{array}$ & $\begin{array}{l}\text { Dispõe sobre o tempo de mandato dos Prefeitos, Vice-Prefeitos e Vereadores e } \\
\text { sobre as eleições para esses cargos no dia } 30 \text { de novembro de 1969; extingue a } \\
\text { Justiça da Paz eletiva; exclui da apreciação judicial atos praticados de acordo com } \\
\text { suas normas e Atos Complementares decorrentes. }\end{array}$ \\
\hline $\begin{array}{l}\text { Ato Institucional } \mathrm{n}^{\circ} 12 \text {, de } 1 \stackrel{\circ}{ } \text { de } \\
\text { setembro de } 1969 \text {. }\end{array}$ & $\begin{array}{l}\text { Confere aos Ministros da Marinha de Guerra, do Exército e da Aeronáutica Militar } \\
\text { as funções exercidas pelo Presidente da República, Marechal Arthur da Costa e Silva, } \\
\text { enquanto durar sua enfermidade; exclui da apreciação judicial atos praticados de } \\
\text { acordo com suas normas e Atos Complementares decorrentes. }\end{array}$ \\
\hline $\begin{array}{l}\text { Ato Institucional no } 13 \text {, de } 5 \text { de } \\
\text { setembro de } 1969 \text {. }\end{array}$ & $\begin{array}{l}\text { Dispõe sobre o banimento do território nacional de brasileiro inconveniente, nocivo } \\
\text { ou perigoso à segurança nacional, mediante proposta dos Ministros de Estado da } \\
\text { Justiça, da Marinha de Guerra, do Exército ou da Aeronáutica Militar; exclui da } \\
\text { apreciação judicial atos praticados de acordo com suas normas e Atos } \\
\text { Complementares decorrentes. }\end{array}$ \\
\hline $\begin{array}{l}\text { Ato Institucional no } 14 \text {, de } 5 \text { de } \\
\text { setembro de } 1969 \text {. }\end{array}$ & $\begin{array}{l}\text { Dá nova redação ao artigo } 15, \S 11 \text { da Constituição Federal de } 1967 \text {; garante a } \\
\text { vigência de Atos Institucionais, Atos Complementares, leis, decretos-leis, decretos e } \\
\text { regulamentos que dispõem sobre o confisco de bens em casos de enriquecimento } \\
\text { ilí́cito; exclui da apreciação judicial atos praticados de acordo com suas normas e } \\
\text { Atos Complementares decorrentes. }\end{array}$ \\
\hline $\begin{array}{l}\text { Ato Institucional no } 15 \text {, de } 11 \text { de } \\
\text { setembro de } 1969 .\end{array}$ & $\begin{array}{l}\text { Dá nova redação ao artigo } 1^{\circ} \text { do Ato Institucional } \mathrm{n}^{\circ} 11 \text {, de } 14 \text { de agosto de } 1969 \text {, } \\
\text { que dispõe sobre as eleições para Prefeito, Vice-Prefeito e Vereadores dos } \\
\text { Municípios; exclui da apreciação judicial atos praticados de acordo com suas } \\
\text { normas e Atos Complementares decorrentes. }\end{array}$ \\
\hline $\begin{array}{l}\text { Ato Institucional no } 16 \text {, de } 14 \text { de } \\
\text { outubro de } 1969 .\end{array}$ & $\begin{array}{l}\text { Declara vacância dos cargos de Presidente e Vice-Presidente da República; dispõe } \\
\text { sobre eleições e período de mandato para esses cargos; confere a Chefia do Poder } \\
\text { Executivo aos Ministros militares enquanto durar a vacância; exclui da apreciação } \\
\text { judicial atos praticados de acordo com suas normas e Atos Complementares } \\
\text { decorrentes; e dá outras providências }\end{array}$ \\
\hline $\begin{array}{l}\text { Ato Institucional } \mathrm{n}^{\circ} 17, \text { de } 14 \text { de } \\
\text { outubro de } 1969 \text {. }\end{array}$ & $\begin{array}{l}\text { Autoriza o Presidente da República a transferir para reserva, por período } \\
\text { determinado, os militares que hajam atentado ou venham a atentar contra a coesão } \\
\text { das Forças Armadas. }\end{array}$ \\
\hline
\end{tabular}

Fonte: BRASIL - Portal da Legislação do Governo Federal (2016)

Alguns pesquisadores afirmam que os AI foram uma espécie de DSN exacerbada, o recrudescimento de seus princípios e métodos, porém o conteúdo do treinamento militar oferecido pela 'Escola das Américas' parece corroborar essa conduta autoritária extremada e repressiva. As implicações do estabelecimento de um Estado de Segurança Nacional no Brasil foram o estado de exceção, as restrições de direitos, a repressão da oposição e da liberdade de expressão (civil e da imprensa), cassações de mandatos 
políticos da oposição, perseguição aos opositores civis e militares etc. Em suma, violações de direitos fundamentais da cidadania democrática, constitucionais e da própria legislação do regime militar, bem como de direitos humanos pelo uso da violência e de técnicas de tortura institucionalizadas pelo Estado de Segurança Nacional do Brasil.

\section{CONSIDERAÇÕES FINAIS}

A bipolaridade resultante da emergência de apenas duas superpotências no sistema internacional contribuiu para a imposição de zonas de influências capitalistas e comunistas, levando a uma divisão ideológica maniqueísta que favoreceu a hegemonia liberal-democrática anticomunista propagada pelos EUA. A Doutrina de Segurança Nacional de Contenção surgiu como meio para a afirmação e propagação da estratégia estadunidense após a II Guerra Mundial e, também, para a criação de mecanismos de defesa e contenção que não apenas combatiam a expansão soviética e comunista, mas controlavam as zonas de influência por meio da assistência internacional.

A pressão internacional movida por uma retórica democrática e desenvolvimentista teve consequências negativas para o Brasil, pois se priorizava o desenvolvimento econômico em detrimento do social (RIBEIRO, 2006, p. 108) e o processo eleitoral como elemento legitimador de uma democracia - mesmo diante de violações constitucionais e de direitos fundamentais da cidadania democrática. Desse modo, o Brasil combinou opostos, como o histórico autoritarismo e o liberalismo econômico, em um regime aparentemente democrático.

A DSNC produziu mais malefícios que benefícios para a América Latina e o Brasil, pois esses países pularam etapas essenciais para a construção de uma sociedade verdadeiramente democrática. No âmbito internacional predominou a segurança do Estado sobre os direitos humanos, enquanto no âmbito nacional predominou a segurança nacional em detrimento dos direitos fundamentais dos cidadãos brasileiros.

As implicações da adoção de princípios estrangeiros no Brasil já são conhecidas ${ }^{16}$ : repressão político-ideológica, golpe militar, manipulação midiática, suspensão de direitos fundamentais, tortura e desaparecimentos, democracia aparente (mas não de fato), atraso

\footnotetext{
${ }^{16}$ Há uma literatura recente que detalha as engrenagens do regime militar, suas práticas repressivas e as violações de direitos humanos. Ver, por exemplo, os arquivos das Comissões Nacionais da Verdade.
} 
cultural, educacional, jurídico e tecnológico em comparação ao ideal propagado pela estratégia estadunidense.

No Brasil, a adoção de uma ideologia de contenção do comunismo e da subversão, aliada ao histórico autoritário e intervencionista do Estado, culminou na institucionalização de ideias e práticas repressivas baseadas na doutrina de segurança nacional estadunidense, reforçando o caráter antidemocrático da sociedade brasileira e a violação de direitos fundamentais de seus cidadãos.

À primeira vista, essa institucionalização, com a criação da Escola Superior de Guerra e as leis de segurança nacional, parece ter acontecido espontaneamente, devido ao interesse brasileiro pelo avanço tecnológico, crescimento e desenvolvimento econômicos. Entretanto, não escapa a um segundo olhar que, ainda que uma parcela da sociedade brasileira percebesse uma real ameaça do comunismo e pretendesse combatê-lo, seus reais propósitos estavam na origem da doutrina: expansão e manutenção da ideologia liberal-democrática para os interesses nacionais dos Estados Unidos.

Se por um lado não é possível quantificar a influência da DSNC na participação dos militares brasileiros na política por meio de uma análise histórica, por outro lado essa metodologia permite traçar os processos e a lógica que renovaram o interesse da elite militar pela política, evidenciando estratégias e mecanismos que, aliados a outros fatores históricos e conjunturais, possibilitaram o estabelecimento de um Estado de Segurança Nacional no Brasil. A articulação das ideologias na percepção de ameaças, poder e oportunidades dos Estados acontece simultaneamente nos âmbitos internacional e nacional que, por vezes, beneficiam ou prejudicam os resultados dos eventos nacionais.

A associação entre segurança e desenvolvimento facilitou a assimilação da DSNC pela elite militar da ESG. Não há dúvida que a DSNC estadunidense contribuiu para a participação dos militares na política brasileira por meio da retórica polarizada da segurança nacional, do medo da ameaça comunista, dos treinamentos e acordos militares, econômicos e tecnológicos, ainda que não seja o único fator relevante para o estabelecimento de um Estado de Segurança Nacional no Brasil.

A participação da FEB na II Guerra Mundial, o interesse pela modernização das forças armadas, a crescente importância atribuída aos militares para o crescimento e desenvolvimento do país, o histórico autoritário e intervencionista e a conjuntura 
político-social à época são fatores igualmente importantes para explicar a institucionalização da DSN na Escola Superior de Guerra, o regime militar instaurado em 1964 e a crescente repressão via Atos Institucionais.

\section{REFERÊNCIAS BIBLIOGRÁFICAS}

BRASIL - Portal da Legislação do Governo Federal. Legislação Histórica: Atos Institucionais (19641969), 2016. Disponível em: <http://www4.planalto.gov.br/legislacao/legislacaohistorica/atos-institucionais>. Acesso em: 14/12/2016.

CARVALHO, José Murillo de. Forças Armadas e Política, 1930-1945. In: Revolução de Trinta Seminário Internacional, p. 113. Brasília: Editora UnB, 1982.

COMBlin, Pe.J. A Ideologia da Segurança Nacional: O Poder Militar na América Latina. Civilização Brasileira: Rio de Janeiro, 1978. ed. 2ª 251 p.

COMPARATO, F.K. A Segurança Nacional. Novos Estudos CEBRAP, São Paulo, v. 1, 1, p. 51-57, dez. 1981.

D'ARAUJO, Maria Celina. Fatos e Imagens - Artigos Ilustrados de Fatos e Conjunturas do Brasil: 0 AI-5. Rio de Janeiro: CPDOC, $2015 . \quad$ Disponível em: <https://cpdoc.fgv.br/producao/dossies/FatosImagens/AI5>. Acesso em: 03/09/2015.

. E Ele Voltou... o segundo Governo Vargas: Comissão Mista Brasil-Estados Unidos. Fundação Getúlio Vargas, CPDOC, Vargas 1951-1954: 2ำ Tempo. Disponível em: http://cpdoc.fgv.br/producao/dossies/AEraVargas2/artigos/EleVoltou/ComissaoMista. Acesso em: 14/12/2016.

EISENHOWER, Dwight D. 48 - Address Before the Council of the Organization of American States. April 12, 1953. Disponível em: http://www.presidency.ucsb.edu/ws/index.php?pid=9816. Acesso em: 14/12/2016.

FICO, C. Versões e Controvérsias sobre 1964 e a Ditadura Militar. Revista Brasileira de História [online]. 2004, vol.24, n.47, pp. 29-60. ISSN 1806-9347.

. Videopalestra “Operação Brother Sam”: mais perguntas. 2011. Acesso em: 20 fevereiro 2013. Disponível em: http://www.brasilrecente.com/2011/02/videopalestra-operacaobrother-sam-mais.html

FGV - Fundação Getúlio Vargas. Diretrizes do Estado Novo (1937 - 1945): A Guerra no Brasil. In: A Era Vargas - dos anos 20 a 1945. Rio de Janeiro: CPDOC, 2015a. Disponível em: <https://cpdoc.fgv.br/producao/dossies/AEraVargas1/anos37-45/AGuerraNoBrasil>. Acesso em: 07/09/2015.

. Diretrizes do Estado Novo (1937 - 1945): Tio Sam chega ao Brasil. In: A Era Vargas - dos anos 20 a 1945. Rio de Janeiro: CPDOC, 2015b. Disponível em: $<$ https://cpdoc.fgv.br/producao/dossies/AEraVargas1/anos3745/AGuerraNoBrasil/TioSam>. Acesso em: 07/09/2015.

. Lei de Segurança Nacional. In: A Era Vargas - dos Anos 20 a 1945. Rio de Janeiro: CPDOC, 2015.2 Disponível em: <https://cpdoc.fgv.br/producao/dossies/AEraVargas1/anos30-

37/RadicalizacaoPolitica/LeiSegurancaNacional>. Acesso em: 10/08/2015. 
FRANÇA, Andrea C. P. Doutrina e Legislação: Os Bastidores da Política dos Militares no Brasil (1964-1985). Dissertação de Mestrado (História Social), Universidade de São Paulo, 2009, $204 \mathrm{p}$.

GOMES, Maria de Fátima C. M. Política Social e Cultura Política. Revista de Políticas Públicas UFMA, São Luis - Maranhão, v.6, n.1, p.113-125, 2002. Disponível em: $<$ www.revistapoliticaspublicas.ufma.br/site/download.php?id_publicacao=769>. Acesso em: 10/08/2015.

GURGEL, J.A.A. Segurança e Democracia: Uma Reflexão Política Sobre a Doutrina da Escola Superior de Guerra. Biblioteca do Exército e Livraria J. Olympio: Rio de Janeiro, 1975. 183 p.

HOBSBAWM, E. Era dos Extremos - O breve século XX, 1914-1991. Companhia das Letras: São Paulo, 2005. ed. $2^{\mathrm{a}}$, reimp. $30^{\mathrm{a}}, 598$ p.

HOOK, Steven W; SPANIER, John. American Foreign Policy Since World War II. Washington, D.C.: Congressional Quarterly Press, 2010.

LEI No 785, de 20 de agosto de 1949 - Cria a Escola Superior de Guerra e dá outras providências. Disponível em: http://www.planalto.gov.br/ccivil_03/leis/1930-1949/L785.htm. Acesso em: 14/12/2016.

LOC - Library of Congress [of the United States]. The Postwar United States, 1945-1968. Disponível em: <http://www.loc.gov/teachers/classroommaterials/presentationsandactivities/presentati ons/timeline/postwar/>. Acesso em: 02/09/2015.

LUNDESTAD, Geir. East, West, North, South: Major Developments in International Politics Since 1945. New York: Sage Publications Ltda., 5aㅡ ed., 2004.

MARES, David R. The National Security State. In: A Companion to Latin American History. Chapter 22, p. 386-405. Oxford, UK: Wiley-Blackwell Publishing Ltd., 2010. (Blackwell Companions of World History)

MD - Ministério da Defesa. Escola Superior de Guerra: 65 anos dedicados ao pensamento sobre Defesa no Brasil. Brasília, 19/08/2014. Disponível em: http://www.defesa.gov.br/noticias/13450-escola-superior-de-guerra-65-anos-dedicadosao-pensamento-sobre-defesa-no-brasil. Acesso em: 14/12/2016.

MEMÓRIAS da Ditadura (Portal). História da Ditadura: períodos da ditadura, 2016. Disponível em: http://memoriasdaditadura.org.br/periodos-da-ditadura/. Acesso em: 14/12/2016.

MINTZ, S., MCNEIL, S. Overview of the Post-War Era. Digital History, 2012. Disponível em: <http://www.digitalhistory.uh.edu/era.cfm?eraID=16>. Acesso em: 02/09/2015.

MONTAGNA, Wilson. A Doutrina de Segurança Nacional. Revista Projeto História, v.6, p. 29-40, PUC-SP, $1986 . \quad$ Disponível em: <http://revistas.pucsp.br/index.php/revph/article/view/12296>. Acesso em: 11/08/2015.

NYE Jr., Joseph. A Guerra Fria. In: Cooperação e Conflito nas Relações Internacionais. Cap. 5, p. 141-195. São Paulo: Editora Gente, 2009.

PAINTER, David S. The Cold War: An international history. London: Routledge, 1999.

PESSOA, M. O Direito da Segurança Nacional. Biblioteca do Exército e Revista dos Tribunais: Rio de Janeiro, 1971. $376 \mathrm{p}$.

REED, B.A. American Foreign Policy in Latin America (1945-1975) - The Containment Policy and the Perceptions of "Threat". University of Pittsburgh, 2011. Thesis (Bachelor in Philosophy) 
REZNIK, L. Democracia e Segurança Nacional: A Polícia Política no Pós-Guerra. FGV: Rio de Janeiro, 2004. 187 p.

RIBEIRO, R. Allagio. A Aliança para o Progresso e as Relações Brasil-EUA. Universidade de São Paulo, 2006. Tese (Doutorado em Ciência Política)

SADER, E. 0 Golpe no Brasil e a Doutrina de Segurança Nacional. 27/03/2012. Acesso em: 25 fevereiro $2013 . \quad$ Disponível em: http://www.cartamaior.com.br/templates/postMostrar.cfm?blog_id=1\&post_id=930

SCHMITTER, Philippe C. Military Rule in Latin America: Functions, Consequences, and Perspectives. London: Sage Publications, 1973.

SEMPA, Francis P. U.S. National Security Doctrines Historically Viewed - A Commentary. American Diplomacy: Foreign Services Despatches and Periodic Reports on U.S. Foreign Policy. Chapel Hill, NC: American Diplomacy Publishers, April/2004. Disponível em: <http://www.unc.edu/depts/diplomat/archives_roll/2004_04-

06/sempa_nsd/sempa_nsd.html>. Acesso em: 08/02/2013.

STEPAN, Alfred. Os Militares na Política - as mudanças de padrões na vida brasileira. Rio de Janeiro, Editora Artenova S.A., 1975.

TRUMAN, Harry S. NSC 68 - A Report to the National Security Council on the United States Objectives and Programs for National Security, April 12, 1950. President's Secretary's File, Truman Papers. Disponível em: https://www.trumanlibrary.org/whistlestop/study_collections/coldwar/documents/pdf/1 0-1.pdf. Acesso em: 14/12/2016.

US Department of State. Democracy. Disponível em: <http://www.state.gov/j/drl/democ/>. Acesso em: 11/08/2015a.

US Department of State - Office of the Historian. A Short History of the Department of State: A New National Security Structure. Disponível em: $<$ http://history.state.gov/departmenthistory/short-history/security>. Acesso em: 03/09/2015.

US Department of State - Office of the Historian. A Short History of the Department of State: Containment and Cold War, 1945-1961. Disponível em: <http://history.state.gov/departmenthistory/short-history/containmentandcoldwar>. Acesso em: 20/01/2013a.

US Department of State - Office of the Historian. A Short History of the Department of State: Containment and Collective Defense. Disponível em: $<$ http://history.state.gov/departmenthistory/short-history/containment>. Acesso em: 20/01/2015b.

US Department of State - Office of the Historian. A Short History of the Department of State: The Truman Doctrine and the Marshall Plan. Disponível em: $<$ https://history.state.gov/departmenthistory/short-history/truman>. Acesso em: 03/09/2015c.

US Department of State - Office of the Historian. Milestones 1961-1968: Alliance for Progress and Peace Corps, 1961-1969. Disponível em: <https://history.state.gov/milestones/19611968/alliance-for-progress>. Acesso em: 20/01/2013b.

US Department of State - Office of the Historian. Milestones 1945-1952: The Truman Doctrine, 1947. Disponível em: <https://history.state.gov/milestones/1945-1952/truman-doctrine>. Acesso em: 03/09/2015d. 
USAID History. Celebrating Fifty Years of Progress. Disponível em: <http://www.usaid.gov/who-we-are/usaid-history>. Acesso em: 22/02/2013.

VIZENTINI, Paulo Fagundes. Relações Internacionais do Brasil - De Vargas a Lula. São Paulo:

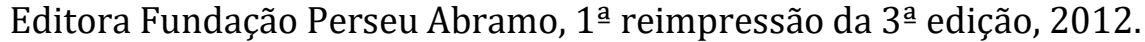

